\title{
Incidence of Second Cancers in Thyroid Cancer Patients Treated with Radioactive Iodine Ablation: How High Is Really the Risk?
}

\author{
Giampiero Giovacchini ${ }^{1 *}$ and Rossella Leoncini ${ }^{2}$ \\ ${ }^{l}$ Institute of Radiology and Nuclear Medicine, Stadtspital Triemli, Zurich, Switzerland \\ ${ }^{2}$ Nuclear Medicine Department, S. Andrea Hospital, La Spezia, Italy
}

(History: received 11 July 2016; revised 12 July 2016; accepted 12 July 2016; published online 12 July 2016)

\begin{abstract}
Differentiated thyroid cancer (DTC) is a common endocrine tumor with increasing incidence and excellent prognosis. The therapy of thyroid cancer consists of thyroidectomy, thyroid hormone treatment and, depending on pathological stage, adjuvant radioactive iodine ablation (RIA). Because of the excellent outcome of DTC and the potential cancerous effect of iodine-131, in the last years there has been a huge number of articles addressing the issue of the incidence of second tumors in DTC patients. We will make a short critical review of some of these articles focusing on results reporting and interpretation. Methodological factors that may affect the obtained results will be highlighted for the benefit of the reader so that the risk associated to iodine-131 exposure will be balanced to the risk associated to other risk factors, including enhanced medical surveillance, shared genetic variability and environment factors and proper methodological study design. The review is finally a call to physicians involved in the therapy of these patients, primarily nuclear medicine physicians, endocrinologists and surgeons, to join their complimentary skill for the therapy of these patients.
\end{abstract}

Keywords: differentiated thyroid cancer; radioactive iodine ablation; second tumors

$\mathrm{T}$ Thyroid cancer is the most commonly diagnosed endocrine tumor and the incidence in thyroid cancer is rising throughout the world $[1,2]$. The therapy of thyroid cancer consists of thyroidectomy, thyroid hormone treatment and, depending on pathological stage, postsurgical radioactive iodine ablation (RIA). Because of the excellent prognosis of differentiated thyroid cancer (DTC) and the fact that radiation exposure represents a risk factor for many other cancers, in the last years there has been an exponential attention to the possible association between RIA and second malignancies in thyroid cancer patients [19].

The topic is of much interest to the nuclear medicine community as well as to the medical community in general, primarily to endocrinologists that in many realities contribute with their nuclear medicine colleagues to the diagnosis and treatment of such patients.

\section{१ิ OPEN ACCESS PEER-REVIEWED}

\section{*Correspondence E-mail: giovacchinig@yahoo.com}

Citation: Giovacchini G, Leoncini R. Incidence of Second Cancers in Thyroid Cancer Patients Treated with Radioactive Iodine Ablation: How High is Really the Risk? Journal of Diagnostic Imaging in Therapy. 2016; 3(1): 49-51. http://dx.doi.org/10.17229/jdit.2016-0712-022

Copyright: (C) 2016 Giovacchini $G$ and Leoncini R. This is an open access article distributed under the terms of the Creative Commons Attribution License (CC By 4.0), which permits unrestricted use, distribution, and reproduction in any medium, provided the original author and source are cited.
In this commentary, we would like to briefly critically review the results of some of the more recent studies and expose our personal perspective. Several studies, comprehensive reviews and at least three meta-analyses on the association between RIA and second cancers have been published in the last years [1-9]. To express our consideration we will select some representative papers of these.

Sawka et al. [2] performed a systematic review and a meta-analysis, which included two multi-center studies, one from Europe [10] and one from North America [6], with a total sample size of 16,502 individuals. The relative risk of second primary malignancies in thyroid cancer survivors treated with RIA was significantly increased at 1.19 (95\% confidence interval: 1.04-1.36) relative to thyroid cancer survivors not treated with RIA, using a minimum latency period of 2 to 3 years after thyroid cancer diagnosis.

The relative risk of leukemia was also significantly increased in thyroid cancer survivors treated with RIA, with a relative risk sizably and equal to 2.5 (95\% confidence interval: 1.13-5.53). The authors did not observe a significantly increased risk of many other cancers: bladder, breast, central nervous system, colon and rectum, digestive tract, stomach, pancreas, kidney (and renal pelvis), lung, or melanoma of skin.

They concluded that the risk of secondary tumors in thyroid cancer survivors treated with RIA is slightly 
increased compared to thyroid cancer survivors not treated with RIA [2].

Clemens et al. performed a systemic review of the literature to examine the risk of intermediate and long-term adverse effects of iodine-131 therapy in differentiated thyroid cancer patients [1]. Their work included 37 studies. After exposure to iodine-131 for DTC, patients experienced significantly more frequently salivary gland dysfunction, lacrimal gland dysfunction, transient male gonadal dysfunction, transient female gonadal dysfunction and secondary cancers (prevalence: $2.7-8.7 \%$, moderate-level evidence) compared to unexposed patients. Importantly, the prevalence and severity of adverse effects were correlated to increasing cumulative iodine-131 activity. The authors concluded that treatment with iodine-131 for DTC may have significant adverse effects, which seem to be dose dependent and these adverse effects of treatment must be balanced when choosing for iodine-131 therapy in patients with DTC [1].

Another interesting article is represented by the one by Kim et al. [3]. The main novelty of the paper by Kim et al. is that they stratified their results according to tumor diameter and therefore they could focus their discussion also on thyroid microcarcinomas ( $\leq 10 \mathrm{~mm}$ or pT1a [11]). We will use this paper also to illustrate some methodological and statistical considerations that lie behind the interpretation of results affecting the association between second tumors and RIA.

The authors accessed the database of the Surveillance, Epidemiology, and End Results (SEER) program for statistical analysis and found an increased risk of second cancers in all sites in thyroid cancer patients. The authors stressed that the increased risk was observed also for thyroid microcarcinomas $(\leq 10 \mathrm{~mm}$ or pT1a [11]) and concluded that aggressive radiation treatment of the primary thyroid cancer, the environment, and genetic susceptibility may increase the risk of a second cancer [3]. In patients with papillary microcarcinomas RIA is associated neither to an improved prognosis nor to a decreased risk of recurrence [12,13].

According to the current guidelines from the European Society of Nuclear Medicine and Molecular Imaging and from the American Thyroid Association there is no indication to radioiodine ablation in papillary microcarcinomas in absence of lymph node or distant metastasis, capsular (pT3). In addition to vascular invasion, history of radiation exposure or unfavorable histology, which includes tall-cell, columnar cell or diffuse sclerosing subtypes, as well as in follicular microcarcinomas [12,13].

Kim et al. report the results on the risk of second cancer by tumor size and treatment in Table 3 . Inspection of Table 3 reveals that all considered tumors, with the exception of leukemia and non-Hodgkin lymphomas, are significantly increased in patients treated only surgically, i.e. never exposed to radioactive iodine. Therefore, the generalized increased incidence of second tumors in thyroid cancer patients is more likely due to factors other than radioiodine ablation, including enhanced medical surveillance, shared genetic variability and environment factors $[6,9,10]$.
For most tumors included in the analysis, patients treated with RIA have a risk that is significantly higher in comparison to the normal population but it is very similar or somehow higher in comparison to patients treated only with surgery. Unfortunately, Kim et al. did not calculate the relative risk across the various treatment groups and therefore it is not possible to establish for which tumors RIA is associated with a significant increase of the risk, with the notable exceptions of non-Hodgkin lymphomas and leukemia, which are significantly increased only in patients treated with radioiodine. Induction of hematological malignancies, in particular leukemia, is the most reproducible oncological risk following radioiodine therapy $[6,7,9,10]$.

Another potential limit of the study is that, contrary to the studies of Sawka et al. [2] and Brown et al. [6], the authors did not provide independent analysis after exclusion of second tumors that were diagnosed in the first two to three years after the diagnosis of thyroid cancer. Such procedure is performed to exclude tumors that are diagnosed before termination of the latency period of the radiation-induced oncogenesis and to account for the increased medical surveillance. A previous study showed that the standardized incidence ratio of all non-thyroid malignancies decreased from about 10 in the first three months after diagnosis to about 2 after three years. However, the statistical significance was maintained for gastric cancer and for leukemia [6].

Use of variable iodine activities on the basis of tumor stage is ongoing in Europe since at least ten years. One of the first studies reporting on the use of low-dose radioiodine ablation in low risk papillary thyroid cancer was performed in Italy in 2003 [14] and two large multicentric studies were performed in France and in England almost ten years later $[15,16]$. Considering the result of Clement et al. [1], i.e. that adverse effects seem to be dose dependent, the rationalization of the activity according to the clinical and pathological characteristics of the patient represents the strategy that must be followed in the future by all physicians involved in the treatment of DTC patients.

\section{CONCLUSION}

In summary, we have provided a short overview of the literature addressing the issue of the incidence of second tumors in DTC patients in relation to RIA. Because of the biological and media relevance of this topic we expect further publications in the near future that will refine details of the complex topic. Proper statistical procedures, such as collection of sufficient number of articles or of papers including huge numbers of patients, exclusion of tumors diagnosed in the first 2-3 years of follow-up, calculation of a relative risk in comparison to patients treated only with surgery, etc. are needed to avoid biased or inconclusive results. While the issue of second tumors is less important in patients with advanced pathological stage, more attention should be addressed, as in the study by Kim et al. [3], to patients with early stage of disease where RIA is in many cases disputable. 
While there is convincing evidence that patients with DTC do have a higher risk of several second cancers, the exact role of radioiodine ablation needs to be further defined and other factors, including enhanced medical surveillance, shared genetic variability and environment factors, likely contribute to the observed findings [6,9,10]. Primary treatment of low-risk papillary thyroid cancer is subject to controversies [17] and collaboration among experts of different specialties is a critical factor for appropriate management of thyroid cancer patients.

\section{Conflicts of Interest}

The authors report no conflicts of interest.

\section{REFERENCES}

Key References: 1, 2, 3, 6

[1] Clement SC, Peeters RP, Ronckers CM, et al. Intermediate and long-term adverse effects of radioiodine therapy for differentiated thyroid carcinoma-a systematic review. Cancer Treat Rev. 2015; 41: 925-934.

CrossRef

[2] Sawka AM, Thabane L, Parlea L, et al. Second primary malignancy risk after radioactive iodine treatment for thyroid cancer: a systematic review and meta-analysis. Thyroid. 2009; 19: 451-457. CrossRef

[3] Kim C, Bi X, Pan D, et al. The risk of second cancers after diagnosis of primary thyroid cancer is elevated in thyroid microcarcinomas. Thyroid. 2013; 23: 575-582.

CrossRef PubMed

[4] Sawka AM, Rilkoff H, Tsang RW, et al. The rationale of patients with early-stage papillary thyroid cancer for accepting or rejecting radioactive iodine remnant ablation. Thyroid. 2013; 23: 246-247. CrossRef

[5] Sawka AM. Iodine radioisotope diagnostic scanning with SPECT/CT after thyroidectomy for thyroid cancer: essential data or unnecessary investigation? J Clin Endocrinol Metab. 2013; 98: 958960.

CrossRef

[6] Brown AP, Chen J, Hitchcock YJ, Szabo A, Shrieve DC, Tward JD. The risk of second primary malignancies up to three decades after the treatment of differentiated thyroid cancer. J Clin Endocrinol Metab. 2008; 93: 504-515.

CrossRef

[7] Ronckers CM, McCarron P, Ron E. Thyroid cancer and multiple primary tumors in the SEER cancer registries. Int J Cancer. 2005; 117: 281-288.

CrossRef

[8] Subramanian S, Goldstein DP, Parlea L, et al. Second primary malignancy risk in thyroid cancer survivors: a systematic review and meta-analysis. Thyroid. 2007; 17: 1277-1288.

CrossRef

[9] Sawka AM, Thephamongkhol K, Brouwers M, Thabane L, Browman G, Gerstein HC. Clinical review 170: A systematic review and metaanalysis of the effectiveness of radioactive iodine remnant ablation for well-differentiated thyroid cancer. $J$ Clin Endocrinol Metab. 2004; 89(8): 3668-3676. Reference Source

[10] Rubino C, Adjadj E, Guerin S, et al. Long-term risk of second malignant neoplasms after neuroblastoma in childhood: role of treatment. Int J Cancer. 2003; 107: 791-796. CrossRef

[11] Thyroid. In AJCC Cancer Staging Manual. 7th edition. Edited by Edge SB, Byrd DR, Compton CC, April GF, Greene FL, Trotti A. New York; 2010: 87-96.

Reference Source
[12] Luster M, Clarke SE, Dietlein M, et al. Guidelines for radioiodine therapy of differentiated thyroid cancer. Eur J Nucl Med Mol Imaging. 2008; 35: 1941-1959.

CrossRef

[13] Cooper DS, Doherty GM, Haugen BR, et al. Revised American Thyroid Association management guidelines for patients with thyroid nodules and differentiated thyroid cancer. Thyroid. 2009; 19: $1167-1214$ CrossRef

[14] Barbaro D, Boni G, Meucci G, et al. Radioiodine treatment with 30 $\mathrm{mCi}$ after recombinant human thyrotropin stimulation in thyroid cancer: effectiveness for postsurgical remnants ablation and possible role of iodine content in L-thyroxine in the outcome of ablation. $J$ Clin Endocrinol Metab. 2003; 88: 4110-4115. CrossRef

[15] Schlumberger M, Catargi B, Borget I, et al. Strategies of radioiodine ablation in patients with low-risk thyroid cancer. $N$ Engl $\mathrm{J}$ Med. 2012; 366: 1663-1673. CrossRef

[16] Mallick U, Harmer C, Yap B, et al. Ablation with low-dose radioiodine and thyrotropin alfa in thyroid cancer. $N$ Engl $\mathrm{J}$ Med. 2012; 366: 1674-1685. CrossRef

[17] McLeod DS, Sawka AM, Cooper DS. Controversies in primary treatment of low-risk papillary thyroid cancer. Lancet. 2013; 381: 1046-1057. CrossRef 